\title{
At-Home Versus In-Clinic INR Monitoring: A Cost-Utility Analysis from The Home INR Study (THINRS)
}

\author{
Ciaran S. Phibbs, PhD ${ }^{7,2,3}$, Sean R. Love 4,5 , Alan K. Jacobson, MD ${ }^{6,7}$, Robert Edson, MA ${ }^{8}$, Pon Su, MS , \\ Lauren Uyeda, $M A^{8}$, and David B. Matchar, $M D^{4,9,10}$ writing for the THINRS Executive Committee and \\ Site Investigators
}

\begin{abstract}
'Health Economics Resource Center, VA Palo Alto Health Care System, Palo Alto, CA, USA; ${ }^{2}$ Department of Pediatrics and Center for Primary Care and Outcomes Research, Stanford University School of Medicine, Stanford, CA, USA; ${ }^{3}$ Health Economist, VA Health Economics Resource Center, Menlo Park, CA, USA; ${ }^{4}$ Health Services and Systems Research Program, Duke-National University of Singapore Graduate Medical School, Singapore, Singapore; ${ }^{5}$ Warren Alpert Medical School of Brown University, Providence, RI, USA; ${ }^{6}$ Jerry L. Pettis VA Medical Center, Research and Development Service (151), Loma Linda, CA, USA; ${ }^{7}$ Department of Internal Medicine, Loma Linda University, Loma Linda, CA, USA; ${ }^{8}$ VA Palo Alto Health Care System, Cooperative Studies Program Coordinating Center (151 K), Palo Alto, CA, USA; 'Durham VA Medical Center, Durham, NC, USA; ${ }^{10}$ Division of General Medicine, Department of Medicine, and Center for Clinical Health Policy Research, Duke University Medical Center, Durham, NC, USA.
\end{abstract}

BACKGROUND: Effective management of patients using warfarin is resource-intensive, requiring frequent inclinic testing of the international normalized ratio (INR). Patient self-testing (PST) using portable at-home INR monitoring devices has emerged as a convenient alternative. As revealed by The Home INR Study (THINRS), event rates for PST were not significantly different from those for in-clinic high-quality anticoagulation management (HQACM), and a cumulative gain in quality of life was observed for patients undergoing PST.

OBJECTIVE: To perform a cost-utility analysis of weekly PST versus monthly HQACM and to examine the sensitivity of these results to testing frequency.

PATIENTS/INTERVENTIONS: In this study, 2922 patients taking warfarin for atrial fibrillation or mechanical heart valve, and who demonstrated PST competence, were randomized to either weekly PST ( $n=1465)$ or monthly inclinic testing $(n=1457)$. In a sub-study, 234 additional patients were randomized to PST once every 4 weeks ( $n=116)$ or PST twice weekly $(n=118)$. The endpoints were quality of life (measured by the Health Utilities Index), health care utilization, and costs over 2 years of follow-up. RESULTS: PST and HQACM participants were similar with regard to gender, age, and $\mathrm{CHADS}_{2}$ score. The total cost per patient over 2 years of follow-up was $\$ 32,484$ for HQACM and $\$ 33,460$ for weekly PST, representing a difference of $\$ 976$. The incremental cost per qualityadjusted life year gained with PST once weekly was $\$ 5566$ (95\% CI, $-\$ 11,490$ to $\$ 25,142)$. The incremental cost-effectiveness ratio (ICER) was sensitive to testing frequency: weekly PST dominated PST twice weekly and once every 4 weeks. Compared to HQACM, weekly PST was

Trial Registration Number: ClinicalTrials.gov NCTO0032591 (https:// clinicaltrials.gov/ct2/show/NCTO0032591)

Electronic supplementary material The online version of this article (doi:10.1007/s11606-016-3700-8) contains supplementary material, which is available to authorized users.

Received May 8, 2015

Revised November 16, 2015

Accepted March 28, 2016

Published online May 27, 2016 associated with statistically significant and clinically meaningful improvements in quality of life. The ICER for weekly PST versus HQACM was well within accepted standards for cost-effectiveness, and was preferred over more or less frequent PST. These results were robust to sensitivity analyses of key assumptions.

CONCLUSION: Weekly PST is a cost-effective alternative to monthly HQACM and a preferred testing frequency compared to twice weekly or monthly PST.

KEY WORDS: anticoagulants; atrial fibrillation; heart valve; cost effectiveness; randomized trials. J Gen Intern Med 31(9):1061-7

DOI: $10.1007 / \mathrm{s} 11606-016-3700-8$

(C) Society of General Internal Medicine 2016

\section{INTRODUCTION}

Although anticoagulation with warfarin is effective in reducing the risk of thromboembolism in patients with atrial fibrillation or a mechanical heart valve, ${ }^{1}$ management requires frequent monitoring of the international normalized ratio (INR) to ensure that an adequate yet safe dose is taken. Failure to maintain the INR in therapeutic range is associated with increased risk of hemorrhage or thromboembolism, depending on the direction of deviation. Although alternatives such as dabigatran offer similar efficacy and do not require frequent blood tests for the INR, warfarin remains the standard pharmacotherapy for patients with atrial fibrillation and a moderate to high risk of thrombosis. ${ }^{2}$.

Given the necessity of frequent monitoring and dosing adjustments, the quality of anticoagulation management with warfarin has been shown to vary widely in clinical practice. ${ }^{3}$ High-quality anticoagulation management (HQACM; management by a dedicated anticoagulation clinic) ${ }^{4}$ is associated with greater time spent in therapeutic range and lower event rates compared to standard clinical practice. ${ }^{5}$ However, conventional laboratory testing of INR, as performed in both HQACM and standard clinical practice, can be inconvenient 
for patients who must travel to a centralized location. ${ }^{6,7}$ In some cases, this may limit the frequency of INR testing as well as access to anticoagulation treatment.

Systematic reviews have supported frequent home monitoring via patient self-testing (PST) of INR as a safe and effective alternative to standard in-clinic testing. ${ }^{6,8-10}$ In 2012, the American College of Chest Physicians revised its clinical practice guidelines to incorporate the use of portable at-home INR testing devices. ${ }^{11}$ The Home INR Study (THINRS), the largest randomized controlled trial of PST $(n=2922)$ to date, found negligible differences in clinical outcomes between weekly PST and once-monthly in-clinic testing via HQACM. ${ }^{7}$ In order to examine the effects of testing frequency, THINRS included a sub-study in which 234 additional patients were randomized to PST twice weekly $(n=118)$ or once every 4 weeks $(n=116)$.

The paper that reported the primary results of THINRS did not include a formal economic analysis; only the differences in mean costs and outcomes between all patients who underwent PST (regardless of frequency) and the HQACM group were reported. ${ }^{7}$ These comparisons revealed a statistically significant improvement in quality-adjusted life years (QALYs), as measured by the Health Utilities Index Mark 3 (HUI), ${ }^{12}$ for the PST group. Costs were somewhat higher in the PST group than in the HQACM group, but this difference was not statistically significant.

The main objective of this study was to conduct a cost utility analysis of weekly PST versus HQACM from the perspective of a health care system. Given that the THINRS test-frequency sub-study found that more frequent test frequency was associated with greater time spent in target INR range, ${ }^{13}$ a secondary objective was to examine the cost-utility of different PST testing frequencies.

\section{METHODS}

\section{Summary of THINRS Design}

THINRS was a two-part prospective, randomized, open-label trial, which has been described previously. ${ }^{7,14}$ Briefly, patients were eligible if they had atrial fibrillation, a mechanical heart valve, or both, and required chronic warfarin therapy for an indeterminate period. In part one, patients were trained to use a portable at-home INR monitoring device, and were evaluated 2 to 4 weeks later for PST competency. ${ }^{14}$ Patients who demonstrated PST competency were eligible for part two of the study, which randomized patients to PST or HQACM. Patients gave separate written informed consent for the two parts of the study, and the research protocol was approved by the appropriate institutional review boards.

THINRS data were collected at 28 Veterans Affairs (VA) Medical Centers with anticoagulation clinics that met HQACM care guidelines, as defined by the Managing Anticoagulation Services Trial (MAST). ${ }^{4}$ This required a centralized, specialized trained anticoagulation service staffed by nurses and/or pharmacists under the supervision of physicians who provide patient education, monitoring, coordination, and routine dosing decisions. All patients were followed for a minimum of 2 years (excluding dropouts and deaths), and could be followed until the end of the trial. After randomization, all patients had scheduled follow-up study visits every 3 months to collect interval information, including quality of life and use of non-VA health care.

\section{Study Sample}

The sample used for this analysis is different from that previously reported. ${ }^{7}$ Figure 1 outlines the differences. Five HQACM and three weekly PST patients were excluded due to incomplete HUI data. The 118 patients randomized to undergo PST twice weekly and 116 patients randomized to undergo PST once every 4 weeks were excluded from the main analysis and were considered separately. The final sample for the main comparison included 1452 HQACM and 1228 weekly PST patients.

\section{Data}

Costs and utilization of VA care were obtained from centralized VA files; the costs were the actual VA production costs. The remaining costs were micro-costed from study data. Patient-completed study forms were used to capture data on non-VA health care utilization and patient travel costs. Mean VA costs for similar types of care were used to assign costs to all non-VA utilization. The IRS-allowed expense rate for travel for medical care was used to assign costs to patient travel. The staff time for training patients on performing PST, verifying PST competence, and monitoring PST were captured from

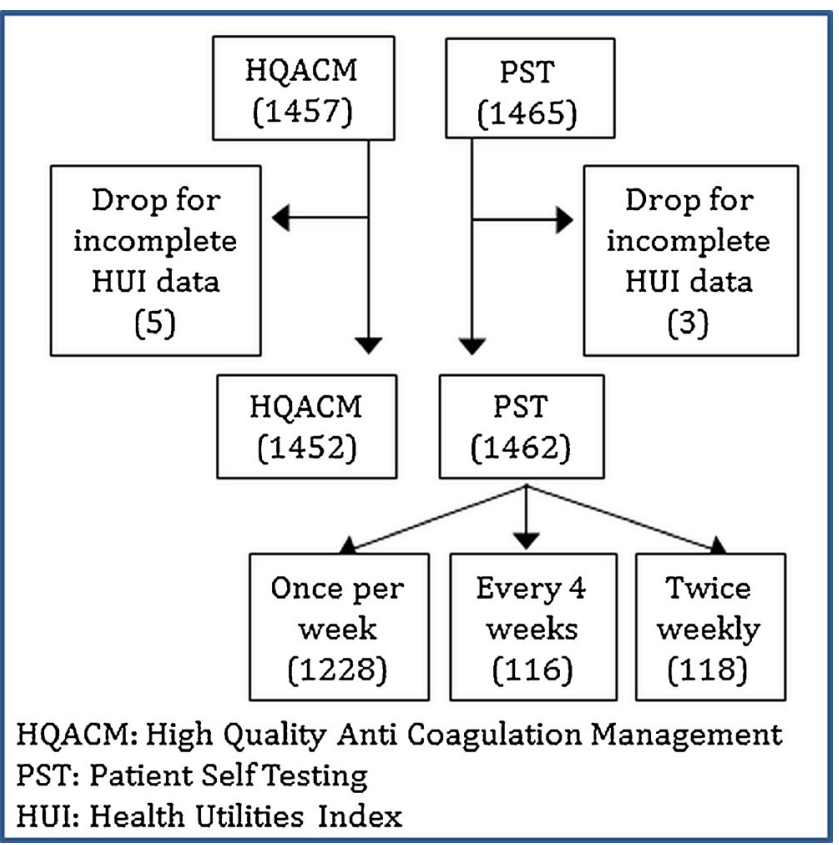

Figure 1 Participants, randomization, and numbers dropped for incomplete HUI data 
study forms. Average VA labor costs for each type of labor were used to calculate the training and monitoring costs. The training costs were inflated to adjust for the fact that only $80 \%$ of the patients in part one of the trial demonstrated competency. ${ }^{15}$ The VA purchase price was used for the cost of the portable at-home INR monitor (\$900) and for the test strips (\$3.00 per strip). The overall Consumer Price Index was used to adjust all costs except the meters and test strips to April 2013 dollars. ${ }^{16}$ Monitor and test strip prices were not adjusted for inflation, given observed price reductions over time, likely associated with the increased demand due to Medicare approval of the use of this technology. A recent check of a major online commercial retailer found monitors available for as low as $\$ 475 .^{17}$

Quality of life was measured by the HUI, which was measured at baseline and at quarterly patient study visits. ${ }^{12}$ The Duke Anticoagulation Satisfaction Scale (DASS) was also measured to assess patient satisfaction with their anticoagulation management, as this could be an important driver of potential utility differences. ${ }^{18}$.

\section{Cost-Utility Analysis}

The gains in QALYs over the2-year period were calculated by summing the HUI using the method described by Fairclough, with deaths assigned an HUI of zero for the remainder of the period. ${ }^{19}$ All costs and utilities were discounted at $3 \%$. The cost-utility analysis was conducted following the methods recommended by the US Public Health Service Task Force. ${ }^{20,21}$ The analyses were conducted from the perspective of the health care system. Only direct costs were included in order to avoid double counting for indirect costs that are theoretically captured in the utility.

A conservative approach was adopted in assessing the costeffectiveness of PST: all up-front costs of initiating PST were attributed to the first 2 years after randomization, and only the QALY differences for the first 2 years of follow-up for which data were available for all patients were included. This approach explicitly ignores any gains in QALYs that accrue after 2 years of follow-up and forces the full costs of the monitor and patient training to be amortized over 2 years. The time horizon was not extended beyond 2 years because complete follow-up data was available for only 2 years.

The statistical analyses (chi-square and Fisher tests for categorical variables and $t$ test and Wilcoxon for continuous variables) were performed using SAS version 9.1.3 (SAS Institute Inc., Cary, NC). Because costs and all of the subcomponents of costs had skewed, $\ln (\operatorname{costs})$ were used for the $t$ tests for cots. The incremental cost-effectiveness ratio (ICER) was defined as the difference in costs between PST and HQACM, divided by the difference in 2-year QALY between PST and HQACM. The bootstrapped cost-effectiveness regions using 1000 samples with replacement were calculated using Stata version 11 (StataCorp LP, College Station, TX) and the userwritten program by Glick. ${ }^{22,23}$.
Sensitivity analyses were conducted to test the effects of results to changes in cost differences, the HUI gains, the length of time that the meter costs were amortized, and changes in the cost of the meter and test supplies. While patient travel costs were not included in the direct costs for the main analyses, because such costs are typically considered an indirect cost, an additional analysis was conducted that included these as a direct non-medical cost. Analyses were also conducted that split the sample into patients with and without a mechanical heart valve, and by length of time on warfarin therapy at baseline.

\section{RESULTS}

\section{Baseline Characteristics}

The baseline characteristics of the 2914 patients in this analysis are reported in Table 1; the statistical comparisons are between HQACM and weekly PST only. Overall, all groups were similar at baseline. Differences between the HQACM and weekly PST groups that reached statistical significance were small and unlikely to be clinically meaningful; for example, the percentage of Hispanic/Latino participants in the HQACM and PST once-weekly groups was 6 and $8 \%$, respectively.

\section{Costs and Health Utility}

Mean health care utilization, costs, and quality of life for all groups are summarized in Table 2. The total cost per patient over 2 years of follow-up was similar between HQACM and weekly PST ( $\$ 32,484$ for HQACM vs. \$33,460 for once-weekly PST), but larger for PST every 4 weeks and twice-weekly PST. While the mean differences in costs and the subcomponents of costs shown ion Table 2 were relatively small, all of the distributions of these costs were skewed, and most of the differences were statistically significant when the natural logarithms of costs were compared. The difference between HQACM and weekly PST was $\$ 975(95 \% \mathrm{CI},-\$ 2074$ to $\$ 4025 ; p=0.53)$. The change from the $\$ 1249$ difference reported previously ${ }^{7}$ is due to the exclusion of the sub-study patients.

After the costs associated with home monitoring were excluded, the costs for the weekly PST patients were slightly lower than those for HQACM; the cost per patient of the meters, supplies, and monitoring averaged \$1605. Consistent with the elimination of the monthly HQACM clinic visits, the only significant difference in utilization between HQACM and weekly PST was 21 fewer outpatient visits, for which the weekly PST patients incurred an average of $\$ 1230$ less in costs. The other PST groups also had reduced outpatient visits.

\section{Cost-Utility}

The cumulative gain in HUI scores ${ }^{19}$ was greatest for weekly PST (1.23) and lowest for HQACM (1.05), the difference between which was statistically significant $(0.176$; $95 \% \mathrm{CI}$, 0.131 to $0.221 ; P<0.001)$. At 2 years of follow-up, 
Table 1 Baseline Characteristics

\begin{tabular}{|c|c|c|c|c|c|}
\hline Characteristic & $\begin{array}{l}\text { HQACM } \\
(n=1452)\end{array}$ & $\begin{array}{l}\text { Weekly } \\
\text { PST } \\
(n=1228)\end{array}$ & $\begin{array}{l}\text { PST every } \\
4 \text { weeks } \\
(n=116)\end{array}$ & $\begin{array}{l}\text { PST twice } \\
\text { weekly } \\
(n=118)\end{array}$ & $P$ value \\
\hline Male gender, no. of patients $(\%)$ & $1426(98 \%)$ & $1207(98 \%)$ & $114(98 \%)$ & $117(98 \%)$ & 0.87 \\
\hline \multicolumn{6}{|l|}{ Age, years } \\
\hline Mean (SD) & $67.4(9.4)$ & $66.6(9.7)$ & $66(10.1)$ & $67(9.5)$ & 0.07 \\
\hline Range & $33-99$ & $32-89$ & $23-86$ & $32-87$ & \\
\hline Ethnicity, Hispanic/Latino, no. of patients $(\%)$ & $90(6 \%)$ & $101(8 \%)$ & $3(3 \%)$ & $4(3 \%)$ & 0.04 \\
\hline \multicolumn{6}{|l|}{ Race*, no. of patients $(\%)$} \\
\hline White & $1343(92 \%)$ & $1139(93 \%)$ & $105(91 \%)$ & $101(85 \%)$ & 0.80 \\
\hline Black & $76(5 \%)$ & $69(6 \%)$ & $10(9 \%)$ & $15(13 \%)$ & 0.66 \\
\hline \multicolumn{5}{|l|}{ Highest level of education, no. of patients $(\%)$} & 0.10 \\
\hline Grades $1-8$ & $62(4 \%)$ & $47(4 \%)$ & $3(3 \%)$ & $7(6 \%)$ & - \\
\hline Grades 9-11 & $122(8 \%)$ & $80(7 \%)$ & $4(3 \%)$ & $12(10 \%)$ & - \\
\hline High school graduate & $411(28 \%)$ & $392(32 \%)$ & $32(28 \%)$ & $25(21 \%)$ & - \\
\hline Some college but no degree & $446(31 \%)$ & $395(32 \%)$ & $42(36)$ & $48(40 \%)$ & - \\
\hline Undergraduate degree & $296(20 \%)$ & $217(18 \%)$ & $22(19 \%)$ & $22(18 \%)$ & - \\
\hline Postgraduate degree & $115(8 \%)$ & $97(8 \%)$ & $13(11 \%)$ & $5(4 \%)$ & - \\
\hline Number of household members & $2.1(1)$ & $2.1(1)$ & $2.1(1)$ & $2.1(1)$ & 0.50 \\
\hline Transport to clinic, did not drive self, no. of patients $(\%)$ & $229(16 \%)$ & $182(15 \%)$ & $21(18 \%)$ & $24(20 \%)$ & 0.50 \\
\hline \multicolumn{5}{|l|}{ Months of anticoagulation treatment, no. of patients $(\%)$} & 0.56 \\
\hline$<3$ & $126(9 \%)$ & $102(8 \%)$ & $5(4 \%)$ & $8(7 \%)$ & - \\
\hline 3 to 6 & $99(7 \%)$ & $70(6 \%)$ & $6(5 \%)$ & $8(7 \%)$ & - \\
\hline$>6$ to 12 & $106(7 \%)$ & $83(7 \%)$ & $6(5 \%)$ & $8(7 \%)$ & - \\
\hline$>12$ & $1121(77 \%)$ & $973(79 \%)$ & $99(85 \%)$ & $95(80 \%)$ & - \\
\hline \multicolumn{6}{|l|}{ Cardiac disorders, no. of patients $(\%)$} \\
\hline Atrial fibrillation & $1216(84 \%)$ & $1008(82 \%)$ & $96(83 \%)$ & $95(80 \%)$ & 0.25 \\
\hline \multicolumn{5}{|l|}{$\begin{array}{l}\mathrm{CHADS}_{2} \text { score, no. of patients and \% of those with } \\
\text { atrial fibrillation only }\end{array}$} & $0.48 \dagger$ \\
\hline 0 & $110(5 \%)$ & $112(5 \%)$ & $7(8 \%)$ & $8(9 \%)$ & - \\
\hline 1 & $328(16 \%)$ & $269(13 \%)$ & $25(29 \%)$ & $29(33 \%)$ & - \\
\hline 2 & $354(17 \%)$ & $280(14 \%)$ & $27(31 \%)$ & $19(22 \%)$ & - \\
\hline 3 & $206(10 \%)$ & $163(8 \%)$ & $16(18 \%)$ & $20(23 \%)$ & - \\
\hline 4 & $82(4 \%)$ & $78(4 \%)$ & $8(9 \%)$ & $10(11 \%)$ & - \\
\hline 5 & $36(2 \%)$ & $30(1 \%)$ & $4(5 \%)$ & $0(0 \%)$ & - \\
\hline 6 & $2(0 \%)$ & $5(0 \%)$ & $0(0 \%)$ & $1(1 \%)$ & - \\
\hline Mean & 1. 94 & 1. 93 & 2.06 & 1.99 & 0.82 \\
\hline Mechanical heart valve & $333(23 \%)$ & $290(24 \%)$ & $29(25 \%)$ & $32(27 \%)$ & 0.68 \\
\hline Aortic & $256(18 \%)$ & $234(19 \%)$ & $19(16 \%)$ & $25(21 \%)$ & 0.34 \\
\hline Mitral & $89(6 \%)$ & $72(6 \%)$ & $11(9 \%)$ & $8(7 \%)$ & 0.77 \\
\hline Other valve & $0(0 \%)$ & $0(0 \%)$ & $0(0 \%)$ & $0(0 \%)$ & - \\
\hline Arrhythmia, not atrial fibrillation & $159(11 \%)$ & $136(11 \%)$ & $8(7 \%)$ & $14(12 \%)$ & 0.92 \\
\hline Congestive heart failure & $431(30 \%)$ & $328(27 \%)$ & $37(32 \%)$ & $39(33 \%)$ & 0.09 \\
\hline Angina & $254(17 \%)$ & $203(17 \%)$ & $17(15 \%)$ & $21(18 \%)$ & 0.51 \\
\hline Diabetes mellitus, no. of patients $(\%)$ & $491(34 \%)$ & $393(32 \%)$ & $41(35 \%)$ & $37(31 \%)$ & 0.32 \\
\hline Hypertension, no. of patients $(\%)$ & $1006(69 \%)$ & $864(70 \%)$ & $88(76 \%)$ & $89(75 \%)$ & 0.55 \\
\hline Previous stroke, no. of patients $(\%)$ & $140(10 \%)$ & $117(10 \%)$ & $9(8 \%)$ & $10(8 \%)$ & 0.92 \\
\hline Average weekly warfarin dose (mg) & $36.1(15.9)$ & $36.6(16.1)$ & $40.2(16.3)$ & $39.1(18.3)$ & 0.56 \\
\hline Median & 35 & 35 & 40 & 35 & - \\
\hline Range & $5-112$ & $5-122.5$ & $14-90$ & $3.2-135$ & - \\
\hline \multicolumn{6}{|l|}{ Antiplatelet medication, no. of patients $(\%)$} \\
\hline Aspirin & $390(27 \%)$ & $325(26 \%)$ & $31(27 \%)$ & $41(34 \%)$ & 0.81 \\
\hline Clopidogrel & $20(1 \%)$ & $20(2 \%)$ & $3(3 \%)$ & $1(1 \%)$ & 0.59 \\
\hline Ticlopidine & $1(0 \%)$ & $0(0 \%)$ & $0(0 \%)$ & $0(0 \%)$ & 1.00 \\
\hline Amiodarone & $112(8 \%)$ & $97(8 \%)$ & $11(9 \%)$ & $10(8 \%)$ & 0.86 \\
\hline
\end{tabular}

* Given subject could be tallied under more than one race category

†Chi-square test for distribution by integer score (0 through 6)

I $P$ values compare HQACM with weekly PST only

HQACM high-quality anticoagulation management, PST patient self-testing

satisfaction with anticoagulation as measured by DASS (lower value indicates higher satisfaction) had a test frequency gradient that was best for twice-weekly PST (45.3) and worst for HQACM (49.2). The difference in DASS scores between the weekly PST and HQACM groups was statistically significant (difference, $-2.3 ; 95 \% \mathrm{CI},-3.9$ to $-0.8 ; P=0.003$ ).

The bootstrapped cost-effectiveness region for the incremental cost per QALY gained associated with once-weekly PST compared to HQACM was $\$ 5566$ (95\% CI, \$-11,490 to $\$ 25,142$ ) (Fig. 2). All of the bootstrapped QALY differences were positive (once-weekly PST preferred to HQACM).
Seventy-three percent of cases are located in the upper right quadrant, indicating that PST is more costly and more effective than conventional management. The remaining $27 \%$ of cases are located in the lower right quadrant, indicating that weekly PST is dominant (i.e., less costly and more effective) compared to HQACM.

The cost-utility comparisons between the different study arms are reported in Table 3. The results are sensitive to test frequency; weekly PST strictly dominated PST once every 4 weeks and twice weekly (i.e., weekly PST was both less expensive and more effective). 
Table 2 Mean per-patient costs and utilization

\begin{tabular}{|c|c|c|c|c|c|}
\hline & \multirow{2}{*}{$\begin{array}{l}\text { HQACM } \\
N=1452 \\
\operatorname{Mean}(S D)\end{array}$} & \multirow{2}{*}{$\begin{array}{l}\text { Weekly PST } \\
N=1228 \\
\operatorname{Mean}(S D)\end{array}$} & \multirow{2}{*}{$\begin{array}{l}\text { PST every } 4 \text { weeks } \\
N=116 \\
\operatorname{Mean}(S D)\end{array}$} & \multirow{2}{*}{$\begin{array}{l}\text { PST twice weekly } \\
N=118 \\
\operatorname{Mean}(S D)\end{array}$} & \multirow[t]{2}{*}{$P$ value $\dagger$} \\
\hline & & & & & \\
\hline Grand total (2 years) & $\$ 32,484(\$ 39,010)$ & $\$ 33,460(\$ 41,389)$ & $\$ 41,596(\$ 49,624)$ & $\$ 40,700(\$ 56,675)$ & 0.53 \\
\hline Annualized cost per person* & $\$ 16,242(\$ 19,505)$ & $\$ 16,730(\$ 20,694)$ & $\$ 20,798(\$ 24,812)$ & $\$ 20,350(\$ 28,338)$ & 0.53 \\
\hline Cost without meter & - & $\$ 16,199(\$ 20,695)$ & $\$ 20,261(\$ 24,813)$ & $\$ 19,813(\$ 28,337)$ & - \\
\hline Cost of meter & - & $\$ 900(\$ 0)$ & $\$ 900(\$ 0)$ & $\$ 900(\$ 0)$ & - \\
\hline Cost of supplies & - & $\$ 408(\$ 148)$ & $\$ 122(\$ 53)$ & $\$ 674(\$ 322)$ & - \\
\hline Cost of training, monitoring and assessment & - & $\$ 297(\$ 152)$ & $\$ 219(\$ 86)$ & $\$ 298(\$ 165)$ & - \\
\hline Acute inpatient costs & $\$ 11,331(\$ 26,203)$ & $\$ 11,838(\$ 31,503)$ & $\$ 16,785(\$ 36,273)$ & $\$ 15,416(\$ 37,442)$ & 0.65 \\
\hline Acute inpatient utilization (days) & $5.59(1559)$ & $6.15(18.35)$ & $7.59(17.50)$ & $7.98(24.42)$ & 0.40 \\
\hline Other inpatient cost & $\$ 1110(\$ 8143)$ & $\$ 811(\$ 6308)$ & $\$ 3054(\$ 10,082)$ & $\$ 4094(\$ 27,682)$ & 0.28 \\
\hline Other inpatient utilization (days) & $2.99(30.32)$ & $1.55(13.56)$ & $7.71(22.71)$ & $12.32(85.01)$ & 0.10 \\
\hline Outpatient cost & $\$ 16,458(\$ 16,937)$ & $\$ 15,228(\$ 13,952)$ & $\$ 17,256(\$ 17,025)$ & $\$ 16,943(\$ 19,226)$ & 0.04 \\
\hline Outpatient visits & $92.08(57.51)$ & $70.7(50.7)$ & $70.00(52.84)$ & $75.55(76.62)$ & $<0.001$ \\
\hline Outpatient pharmacy cost & $\$ 3622(\$ 3728)$ & $\$ 3817(\$ 3702)$ & $\$ 4836(\$ 7046)$ & $\$ 4131(\$ 3922)$ & 0.18 \\
\hline DASS score at 2 years* & $49.2(17.9)$ & $46.9(16.1)$ & $47.2(19.3)$ & $45.3(16.2)$ & 0.003 \\
\hline 2-year HUI & $1.05(0.62)$ & $1.23(0.56)$ & $1.06(0.63)$ & $1.11(0.61)$ & $<0.001$ \\
\hline
\end{tabular}

* Not all patients had a DASS at 2 years. These data are for the 962 PST and 929 HQACM patients with a 2-year DASS $\uparrow P$ values compare HQACM with weekly PST only

HQACM high-quality anticoagulation management, PST patient self-testing, DASS Duke Anticoagulation Satisfaction Scale

\section{Sensitivity Analysis}

To test the assumptions of the analyses, extensive sensitivity analyses were conducted, the results of which are reported in the online Appendix. The results were robust to large changes in QALY gains. The results were more sensitive to changes in costs, but increasing the cost differential by one standard deviation increased the ICER to only $\$ 14,381$. If the meter costs are amortized over the 5 years that the Centers for Medicare and Medicaid Services use as the basis for reimbursement for home INR monitoring, the ICER decreases to \$2477. Including patient travel costs as a non-medical direct cost decreases the ICER to \$4914. The ICER was lower for patients with a mechanical heart value $(\$ 2753)$ than for those

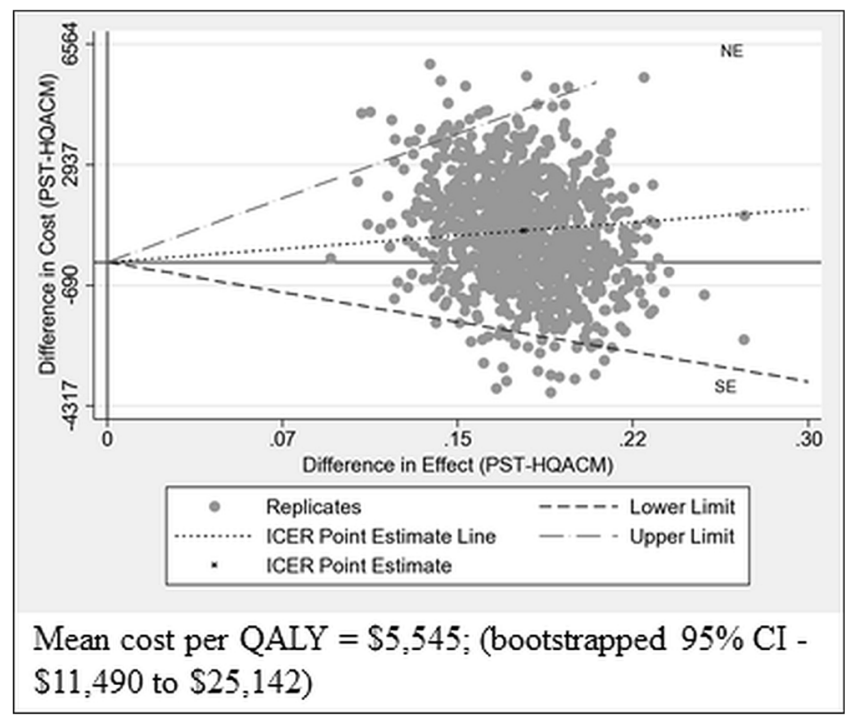

Figure 2 Bootstrapped scatterplot of the incremental cost-effectiveness ratio (ICER) for the weekly patient self-testing (PST) and monthly testing via high-quality anticoagulation management (HQACM) groups with atrial fibrillation only (\$6641). The ICER was higher for patients who had been on warfarin for fewer than 12 months at baseline (\$8584) than for those who had been on warfarin for greater than 12 months $(\$ 5041)$.

\section{DISCUSSION}

The results of THINRS, the largest trial to date of point-of-care INR testing, found a negligible difference between PST and HQACM in preventing major clinical outcomes. However, THINRS showed that PST yielded modest improvements in time in therapeutic range, quality of life, and patient satisfaction with anticoagulation therapy. ${ }^{6}$ The average gain in HUI (about 0.09 QALYs per year) for the once-weekly PST group is well above the recognized minimum value of 0.03 for a clinically meaningful difference. ${ }^{24,25}$ This gain came at an additional cost of less than $\$ 1000$, resulting in an ICER of $\$ 5566$, which is well below the commonly accepted standard for cost-effectiveness of $\$ 50,000$ per QALY. $^{26}$ In fact, given that approximately one quarter of the bootstrapped replications showed net cost savings, it is possible that this technology could save money while improving quality of life. Together, these results show that home INR monitoring is a costeffective technology that should be considered for those who demonstrate PST competence.

The results were robust to sensitivity analyses for the key assumptions; the largest ICER from the sensitivity analyses was $\$ 14,381$. The results are more sensitive to changes in costs than to changes in outcomes. Results varied somewhat for different subgroups, but remained cost-effective for all. Compared to weekly PST, no benefit in QALYs or cost was observed for more or less frequent PST, suggesting that weekly testing is a reasonable default frequency for PST. 
Table 3 Cost Effectiveness by PST Frequency

\begin{tabular}{lllll}
\hline \hline & $\begin{array}{l}\text { 2-year } \\
\text { total cost }\end{array}$ & $\begin{array}{l}\text { Effectiveness (2-year } \\
\text { quality-adjusted life } \\
\text { years [QALYs]) }\end{array}$ & $\begin{array}{l}\text { Incremental cost vs. } \\
\text { next less costly } \\
\text { intervention }\end{array}$ & $\begin{array}{l}\text { Incremental effectiveness } \\
\text { vs. next less costly } \\
\text { intervention }\end{array}$ \\
\hline HQACM & $\$ 32,484$ & 1.051 & $-\begin{array}{l}\text { Incremental cost- } \\
\text { effectiveness ratio } \\
\text { (ICER) }\end{array}$ & - \\
PST weekly & $\$ 33,460$ & 1.226 & $\$ 974$ & 0.175 \\
PST twice weekly & $\$ 40,700$ & 1.112 & $\$ 7240$ & -0.114 \\
PST every 4 weeks & $\$ 41,596$ & 1.050 & $\$ 896$ & -0.062 \\
\hline
\end{tabular}

* The upper $95 \%$ confidence interval for ICER based on bootstrap is $\$ 25,142 / Q A L Y$

HQACM high-quality anticoagulation management, PST patient self-testing

Given that the major clinical event rate did not differ significantly between groups, it is likely that the gains in QALYs for the weekly PST group were associated with the observed improvement in patient satisfaction with anticoagulation management (as measured by DASS), the reduction in clinic visits for INR monitoring, and perhaps an increased sense of patient empowerment and control.

It is notable that the ICER for PST versus HQACM is likely to be a conservative estimate. As noted above, in the main analysis, the full cost of the meter was amortized over 2 years and did not include patient travel costs or quality-of-life gains beyond 2 years. Sensitivity analyses showed that relaxing the two cost assumptions reduced the ICER to $\$ 1829$. Sensitivity analyses that included changes in quality of life beyond 2 years were not conducted, as assumptions about such changes would have been conjecture. However, the sensitivity analyses that varied the changes in utilities as measured by HUI indicated that any changes would probably be modest. Also, while the cost of travel was considered in a sensitivity analysis, patient time was not. Patient time cost is usually considered a productivity cost and thus not included in a costeffectiveness analysis, but some have argued that such costs are direct non-medical costs, and have advocated for of this class of patient time costs. ${ }^{27} \mathrm{Had}$ the time for patient travel or any other patient time costs that were not measured been included in the cost calculation, the ICER would have been even more attractive for PST.

The feature of this analysis that one might argue most substantially biases the results against PST is that only evidence from THINRS was included, in which no statistically significant benefit was seen in major events: stroke, major bleed, or death. Based on evidence that "usual care" is often suboptimal, ${ }^{4}$ and that the control subjects were managed by anticoagulation clinics that met standards for high-quality management, it is reasonable to conjecture that this could have reduced events in the control subjects. A meta-analysis that pooled individual patient data, which included data from THINRS, suggests that PST may indeed reduce the incidence of major events. If PST actually does reduce major events, then the ICER would be even more attractive for PST, and possibly even dominant (i.e., offering better outcomes at lower costs). ${ }^{9}$

One limitation of this study is that all participants came from the VA population. While the care provided by the VA is reflective of mainstream US medical care, the patient population differs from the general population in several ways. Most notably, the VA population is predominately male and comprises relatively few minorities. Furthermore, VA patients tend to have more comorbid conditions and lower income, but similar educational achievement, compared to the general population. The age-adjusted education attainment of THINRS patients was actually somewhat higher than that of non-veterans. ${ }^{28}$ However, it is unclear how these differences may have influenced results. Other data have shown that the overall VA warfarin prescription rate is consistent with North American norms. ${ }^{29}$ One can only speculate whether a more broadly representative population would have experienced an even greater improvement in quality of life from PST over conventional in-clinic testing.

Anticoagulation with warfarin remains well established as an effective treatment for thromboembolism. One traditional challenge to its use has been the need for frequent patient visits for testing and dose adjustment. This study provides important evidence that the improvement in quality of life associated with self-testing can be achieved at a reasonable cost. These results support further efforts to expand the availability of technologies that engage patients in their care.

\section{ACKNOWLEDGEMENTS:}

Contributors: The authors wish to acknowledge the following individuals for the support and guidance they provided, without which the THINRS study would not have been possible: Timothy J. O'Leary, MD, $\mathrm{PhD}$, Chief Research and Development Officer, Office of Research and Development; Grant D. Huang, MPH, PhD, MPH, Deputy Director, Cooperative Studies Program; Ying $\mathrm{Lu}, \mathrm{PhD}$, Director, Palo Alto Cooperative Studies Program Coordinating Center; Mei-Chiung Shih, PhD, Deputy Director and Acting Associate Center Director for Science and Technology and Senior Biostatistician, Palo Alto Cooperative Studies Program Coordinating Center.

Corresponding Author: Ciaran S. Phibbs, PhD; Health EconomistVA Health Economics Resource Center, 795 Willow Road (152MPD), Menlo Park, CA 94025, USA (e-mail: CiaranPhibbs@va.gov; cphibbs@stanford.edu).

\section{Compliance with Ethical Standards:}

Funding: This material is based on research supported by the Department of Veterans Affairs, Veterans Health Administration, Office of Research and Development, Clinical Sciences Research and Development Service, Cooperative Studies Program. Support for Dr. Matchar and Mr. Love was provided by a Singapore Translational Research Investigator Award from the Singapore National Medical Research Council [NMRC STaR/000502008 to DB Matchar]. 
Conflicts of Interest: Alan Jacobson reports consultancy for Boehringer Ingelheim and honoraria and grant support from Microvisk Ltd. All other authors declare that they do not have a conflict of interest.

Prior Presentations: None.

\section{REFERENCES}

1. Ansell J, Hirsh J, Hylek E, Jacobson A, Crowther M, Palareti G. Pharmacology and management of the vitamin K antagonists: American College of Chest Physicians Evidence-Based Clinical Practice Guidelines (8th Edition). Chest. 2008;133:160S-198S.

2. Adam SS, McDuffie JR, Ortel TL, Williams JW Jr. Comparative effectiveness of warfarin and new oral anticoagulants for the management of atrial fibrillation and venous thromboembolism: a systematic review. Ann Intern Med. 2012;157:796-807.

3. Matchar DB, Samsa GP, Cohen SJ, Oddone EZ, Jurgelski AE. Improving the quality of anticoagulation of patients with atrial fibrillation in managed care organizations: results of the managing anticoagulation services trial. Am J Med. 2002;113:42-51.

4. Matchar DB, Samsa GP, Cohen SJ, Oddone EZ. Community impact of anticoagulation services: rationale and design of the Managing Anticoagulation Services Trial (MAST). J Thromb Thrombolysis. 2000;9(Suppl 1):S7-11.

5. Chiquette E, Amato MG, Bussey HI. Comparison of an anticoagulation clinic with usual medical care: anticoagulation control, patient outcomes, and health care costs. Arch Intern Med. 1998;158:1641-1647.

6. Garcia-Alamino JM, Ward AM, Alonso-Coello P, et al. Self-monitoring and self-management of oral anticoagulation. Cochrane Database Syst Rev 2010:CD003839.

7. Matchar DB, Jacobson A, Dolor R, et al. Effect of home testing of international normalized ratio on clinical events. $N$ Engl $\mathrm{J}$ Med. 2010;363:1608-1620.

8. Christensen TD, Johnsen SP, Hjortdal VE, Hasenkam JM. Selfmanagement of oral anticoagulant therapy: a systematic review and meta-analysis. Int J Cardiol. 2007; 118:54-61.

9. Heneghan C, Ward A, Perera $\mathbf{R}$, et al. Self-monitoring of oral anticoagulation: systematic review and meta-analysis of individual patient data. Lancet. 2012;379:322-334.

10. Samsa GP, Matchar DB. Relationship between test frequency and outcomes of anticoagulation: a literature review and commentary with implications for the design of randomized trials of patient self-management. J Thromb Thrombolysis. 2000;9:283-292.

11. Holbrook A, Schulman S, Witt DM, et al. Evidence-based management of anticoagulant therapy: Antithrombotic Therapy and Prevention of Thrombosis, 9th ed: American College of Chest Physicians Evidence-Based Clinical Practice Guidelines. Chest. 2012;141:e152S-184S

12. Horseman J, Furlong W, Feeny D, Torrance G. The Health Utilities Index (HUI®): Concepts, Measurement Properties and Applications. Health and Quality of Life Outcomes (electronic journal). 2003;1.
13. Matchar DB, Love SR, Jacobson AK, et al. The impact of frequency of patient self-testing of prothrombin time on time in target range within VA Cooperative Study \#481: The Home INR Study (THINRS), a randomized, controlled trial. J Thromb Thrombolysis. 2015;40:17-25.

14. Matchar DB, Jacobson AK, Edson RG, et al. The Impact of Patient SelfTesting of Prothrombin Time for Managing Anticoagulation: Rationale and Design of VA Cooperative Study \#481-The Home INR Study (THINRS). J Thromb Thrombolysis. 2005; 19:163-172.

15. Dolor RJ, Ruybalid RL, Uyeda L, et al. An evaluation of patient selftesting competency of prothrombin time for managing anticoagulation: prerandomization results of VA Cooperative Study \#481-The Home INR Study (THINRS). J Thromb Thrombolysis. 2010;30:263-275.

16. CPI Tables. www.bls.gov/cpi/\#tables. Accessed 3 February 2016.

17. Amazon.com: INR meter. http://www.amazon.com/s/ref=nb_sb_noss_2? url=search-alias\%3Daps\&field-keywords=INR+meter. Accessed 3 February 2016.

18. Samsa G, Matchar DB, Dolor RJ, et al. A new instrument for measuring anticoagulation-related quality of life: development and preliminary validation. Health Qual Life Outcomes. 2004;2:22.

19. Fairclough D. Design and Analysis of Quality of Life Studies in Clinical Trials. Boca Raton, FL: Chapman \& Hall/CRC; 2002.

20. Weinstein MC, Siegel JE, Gold MR, Kamlet MS, Russell LB. Recom mendations of the Panel on Cost-effectiveness in Health and Medicine. J Am Med Assoc. 1996;276:1253-1258.

21. Siegel JE, Weinstein MC, Russell LB, Gold MR. Recommendations for reporting cost-effectiveness analyses. Panel on Cost-Effectiveness in Health and Medicine. J Am Med Assoc. 1996;276:1339-1341.

22. Glick H. Web Resources for Economic Evaluation in Clinical Trials. 2012 http://www.uphs.upenn.edu/dgimhsr/eeinct.htm. Accessed 3 February 2016.

23. Glick H, Doshi J, Sonnad S, Polsky D. Economic evaluation in clinical trials. Oxford, UK: Oxford University Press; 2007.

24. Drummond M. Introducing economic and quality of life measurements into clinical studies. Ann Med. 2001;33:344-349.

25. Samsa G, Edelman D, Rothman ML, Williams GR, Lipscomb J, Matchar D. Determining clinically important differences in health status measures: a general approach with illustration to the Health Utilities Index Mark II. PharmacoEconomics. 1999; 15:141-155.

26. Table: Threshold values for intervention cost-effectiveness by Region. http://www.who.int/choice/costs/CER_levels/en/index.html. Accessed 3 February 2016.

27. Russell LB. Completing costs: patients' time. Med Care. 2009;47:S89-93.

28. Holder KA. The Educational Attainment of Veterans: 2007. 2009; https:// www.census.gov/hhes/veterans/files/veteranseducation.pdf. Accessed 3 February 2016.

29. Turakhia MP, Hoang DD, Xu X, et al. Differences and trends in stroke prevention anticoagulation in primary care vs cardiology specialty management of new atrial fibrillation: The Retrospective Evaluation and Assessment of Therapies in AF (TREAT-AF) study. Am Heart J. 2013;165:93-101. 